\title{
Inflammation is Associated with Vascular Remodeling - Repairing Balances in Hypertensive Obese Subjects
}

\author{
Lies Gantini ${ }^{1,2}$, Syakib Bakri ${ }^{1}$, Andi Wijaya ${ }^{1,2}$, Anwar Santoso $^{3}$
}

\begin{abstract}
${ }^{1}$ Post Graduate Program in Clinical Biochemistry, Hasanuddin University, Jl. Perintis Kemerdekaan Km 10, Makassar, Indonesia ${ }^{2}$ Prodia Clinical Laboratory, Jl. Cisangkuy No.2, Bandung, Indonesia

${ }^{3}$ National Cardiovascular Centre, Harapan Kita Hospital, Jl. Let. Jend. S. Parman Kav 87 Slipi, Jakarta, Indonesia *Correspondence: lies.gantini@prodia.co.id
\end{abstract}

\section{Abstract}

$\mathrm{B}$ ACKGROUND: Hypertension and obesity are proinflammatory conditions. Vascular remodeling is one of the pathomechanisms reflecting increased cardiovascular $(\mathrm{CV})$ risks and represented as ratio of MMP-9 and sVEGFR-2 concentration. There is no association confirmed between inflammation and remodeling yet. This study was conducted to investigate the correlation between inflammation and vascular remodeling-repairing balances in hypertensive obese subjects.

METHODS: This was a cross-sectional study recruited 34 hypertensive obese subjects and 10 hypertensive non obese subjects. They had no antihypertensive medications, neither diabetics nor renal disease and nor acute inflammation detected. Inflammation was assessed as increased hsCRP concentration. Vascular remodeling and repairing were consecutively represented by ratio of MMP-9 and sVEGFR-2.

RESULTS: Concentration of hsCRP and MMP-9 were significantly higher in hypertensive obese group than non obese group $(2.094 \pm 1.90$ vs $0.714 \pm 0.40 \mathrm{mg} / \mathrm{L} ; \mathrm{p}$ $=0.029 ; 363.43 \pm 143.64$ vs $261.15 \pm 61.13 \mathrm{ng} / \mathrm{mL}, \mathrm{p}=$ 0.035 , respectively), nonetheless no significant differences of sVEGFR-2 concentration $(9.77 \pm 2.30$ vs $9.76 \pm 1.38$ $\mathrm{pg} / \mathrm{mL}, \mathrm{p}=0.980$ ) found in both groups. Ratio of MMP9/sVEGFR-2 was significantly higher in hypertensive obese group than those in non-obese group $(38.67 \pm 16 \mathrm{vs}$
$27.22 \pm 10, p=0.038)$. Likewise, they had more subjects with ratio of MMP-9/sVEGFR-2 $\geq 31.53$. This figure is considered as cut-off point of vascular remodeling versus repairing.

CONCLUSION: In hypertensive obese subjects, inflammation was activated and vascular remodeling more dominant than repairing process. Inflammation was associated with increased remodeling-repairing balances.

KEYWORDS: Matrix Metalloproteinase-9 (MMP-9), soluble Vascular Endothelial Growth Factor Receptor-2 (sVEGFR-2), high sensitivity C-Reactive Protein (hsCRP).

Indones Biomed J 2011 ; 3 (2) : 110-115

\section{Introduction}

Hypertension and obesity are risk factors of cardiovascular (CV) events. Epidemiological studies have revealed a strong relationship between obesity and hypertension. The Framingham Heart Study shows that $65 \%$ of the risk for hypertension in women and $78 \%$ in men are associated with obesity. Hyperinsulinemia, hyperleptinemia, hypercortisolemia, and renal dysfunction, enhanced symphatetic and renin-angiotensin system activity stand out as important mechanism of obesity hypertension as well as vascular remodeling $(1,2,3,4,5)$. 
Vascular remodeling is one of pathomechanisms of atherosclerosis that causes $\mathrm{CV}$ events. It is an active process of structural alteration, such as: cell growth, apop-tosis, inflammation and fibrosis. It is dependent on dynamic interaction between locally generated growth factors, vasoactive subtances and hemodynamic stimuli $(6,7,8)$.

Hypertension and obesity are obviously known as proinflammatory conditions. Some cross-sectional and cohort studies reported that plasma inflammatory markers such as C-Reactive Protein (CRP) increased in hypertension and obesity subjects compared to normotensive and non-obese subjects $(9,10)$.

Inflammation, growth and apoptosis of smooth muscle cells and vascular fibrosis are dynamic process that affect vascular remodeling. It is likely that inflammation and increased oxidative stress act as an important trigger and may to a large extent be Angiotensin-II or Endothelin-1 dependent, play a role in the process leading to vascular remodeling. Until recently, there is still lack of evidence of the association between inflammation and vascular remodeling-repairing in hypertension. (6)

Plasma Matrix Metalloproteinase-9 (MMP-9) is a type gelatinase-B digests gelatin type IV and V collagen. Some studies reported increased MMP-9 activity as a marker of remodeling process in hypertension population. Vascular Endothelial Growth Factor Receptor-2 (VEGFR-2) plays a central role in the proliferation and apoptosis of vascular endothelium. Depletion of VEGFR-2 signalling leads to apoptosis in capillaries. The experimental model hypertension Spontaneous Hypertensive Rats (SHR) has elevated of proteolitic activity (e.g.MMP) and apoptosis in microvascular cells compared to its normotensive control $(12,13)$.

This study was aimed to investigate the correlation beetween hs-CRP with vascular remodeling - repairing balances using Matrix Metalloproteinase-9 (MMP-9) as a biomarker of remodeling and soluble Vascular Endothelial Growth Factor Receptor-2 (sVEGFR-2) as a biomarker of repairing.

\section{Methods}

This was cross-sectional study conducted at Prodia Clinical Laboratory (June 2009-February 2010). The study subjects were hypertensive patients who had no oral antihypertensive drugs. Hypertension was defined according to JNC 7 (2003) (11). Central obesity was determined by waist circumferences Asia Pacific's criteria $\geq 90 \mathrm{~cm}$ for men and $\geq 80 \mathrm{~cm}$ for women. All participants did not have diabetes mellitus (fasting blood glucose $(\mathrm{FBG})<126 \mathrm{mg} / \mathrm{dL})$, chronic kidney disease $\left(\mathrm{eGFR}_{\mathrm{MDRD}}\right.$ $>60 \mathrm{ml} /$ minute), or acute inflammation detected (hsCRP $<10 \mathrm{mg} / \mathrm{L}$ ). The study protocol has been approved by
The Health Research Ethics Committee of The Faculty of Medicine Hasanuddin University of Makassar.

Level of hsCRP was measured by sensitive immunometric assay method (DPC), MMP-9 was assayed with Enzyme Linked Immunosorbent Assay kit (R\&D Systems) and sVEGFR-2 with Enzyme Linked Immunosorbent Assay kit (R\&D Systems). Serum was separated from whole blood after being centrifuged $1300-1500 \mathrm{~g}$ for 10 minutes and immediately kept at $-20^{\circ} \mathrm{C}$ until assays. All assays were performed according to the manufacturers' instruction. For each assay, MMP-9 and sVEGFR-2 controls were included.

Statistical analyses were performed with the SPSS for Windows version 13.0 software (SPSS Inc., Chicago, IL, USA). Distributions of continuous variables were assessed for normality using Kolmogorov-Smirnov test and for variance homogeneity using Leven's test. Results were shown as mean \pm SD. Pearson correlation analyses were used to test association between variables. The results were narrated and explained by tables and graphs. For statistical test, we used $5 \%$ to define the level of significance.

\section{Results}

This study recruited 34 hypertensive obese subjects and 10 hypertensive non obese subjects who had fullfilled the study criteria, done from June 2009 to February 2010. There were no significant differences in age, blood pressure, blood glucose and estimated glomerular filtration rate (eGFR using MDRD formula) ( $\mathrm{p} \geq 0.05$ ) between these two groups. On the other hand, there were significantly greater value in height, weight and waist circumferences in hypertensive obese subjects compared to hypertensive non obese subjects $(\mathrm{p}<0.05)$. (Table 1$)$.

Further more, levels of hsCRP and MMP-9 were significantly elevated in hypertensive obese compared to those in hypertensive non obese group (2.094 \pm 0.190 vs $0.714 \pm 0.40 \mathrm{mg} / \mathrm{L}, \mathrm{p}=0.029,363.43 \pm 143.64$ vs $261.15 \pm 61.13 \mathrm{ng} / \mathrm{mL}, \mathrm{p}=0.035$ ). No significant differences of sVEGFR-2 concentration $(9.77 \pm 2.30$ vs $9.76 \pm 1.38 \mathrm{pg} / \mathrm{mL}, \mathrm{p}=0.980$ ) between hypertensive obese and hypertensive non obese group were noticed. Ratio of MMP-9/sVEGFR-2 was significantly higher in hypertensive obese compared to hypertensive non obese group ( $38.67 \pm 16$ vs $27.22 \pm 10.38, p=0.038)$. (Table 2). 
Range of MMP-9/sVEGFR-2 ratio were 10.72 -72.9 and the median value was 31.53. Due to no reference estimate for MMP-9/sVEGFR-2 ratio available, so value of 31.53 was used as cut off point. Ratio of MMP-9/sVEGFR-2 $\geq 31.53$ was assumed to reflect the dominant remodeling over repairing process. Table 3 showed differences of MMP-9/sVEGFR-2 ratio between hypertensive non obese and hypertensive obese group. In hypertensive obese group, less subjects had MMP-9/ sVEGFR- 2 of $\geq 31.53$. The differences were statistically significant, and conveyed the inference that remodeling process was more prevailing than repairing.

Table 1. Clinical and biochemical characteristics of Hypertensive Non Obese and Hypertensive Obese Subjects

\begin{tabular}{lccc}
\hline Parameter & $\begin{array}{c}\text { Hypertensive Non Obese } \\
(\mathbf{n}=\mathbf{1 0}) \\
\text { Mean } \pm \text { SD }\end{array}$ & $\begin{array}{c}\text { Hypertensive Obese } \\
(\mathbf{n}=\mathbf{3 4}) \\
\text { Mean } \pm \text { SD }\end{array}$ & $\mathbf{p}$ \\
\hline Age (year) & $48.65 \pm 7.43$ & $49.06 \pm 6.67$ & 0.809 \\
Height $(\mathrm{cm})$ & $162.12 \pm 7.81$ & $157.52 \pm 8.77$ & $0.022^{*}$ \\
Weight $(\mathrm{kg})$ & $58.29 \pm 7.88$ & $68.00 \pm 10.42$ & $0.000^{*}$ \\
Waist Circumference $(\mathrm{cm})$ & $80.85 \pm 6.32$ & $93.71 \pm 7.33$ & $0.000^{*}$ \\
SBP $(\mathrm{mmHg})$ & $125.38 \pm 20.15$ & $135.00 \pm 22.65$ & 0.052 \\
DBP $(\mathrm{mmHg})$ & $83.46 \pm 12.63$ & $87.95 \pm 12.65$ & 0.131 \\
FBG $(\mathrm{mg} / \mathrm{dL})$ & $91.08 \pm 12.46$ & $93.11 \pm 10.55$ & 0.468 \\
Creatinine $(\mathrm{mg} / \mathrm{dL})$ & $0.85 \pm 0.22$ & $0.77 \pm 0.18$ & 0.141 \\
eGFR & $105.77 \pm 35.01$ & $114.03 \pm 29.28$ & 0.293 \\
& & & \\
\hline
\end{tabular}

SBP = Systolic Blood Pressure; DBP = Diastolic Blood Pressure; FBG = fasting blood glucose $;$ GFR = Glomerular Filtration Rate; MDRD = Modified Diet of Renal Disease, SD = Standard Deviation; $p=$ probability "unpaired t test" result test; * ${ }^{*}$ significance $(p<0.05)$.

Table 2. Biochemical markers of Hypertensive Non Obese and Hypertensive Obese Group

\begin{tabular}{lccc}
\hline Variables & $\begin{array}{c}\text { Hypertensive Non Obese } \\
(\mathbf{n}=10) \\
\text { Mean } \pm \text { SD }\end{array}$ & $\begin{array}{c}\text { Hypertensive Obese } \\
(\mathbf{n}=34) \\
\text { Mean } \pm \text { SD }\end{array}$ & $\mathbf{p}$ \\
\hline hsCRP $(\mathrm{mg} / \mathrm{L})$ & $0.714 \pm 0.40$ & $2.094 \pm 1.90$ & $0.029^{*}$ \\
MMP-9 $(\mathrm{ng} / \mathrm{mL})$ & $261.15 \pm 61.13$ & $363.43 \pm 143.64$ & $0.035^{*}$ \\
sVEGFR-2 $(\mathrm{ng} / \mathrm{mL})$ & $9.76 \pm 1.38$ & $9.77 \pm 2.30$ & 0.980 \\
MMP-9/sVEGFR-2 & $27.22 \pm 10$ & $38.67 \pm 16$ & $0.038^{*}$ \\
\hline
\end{tabular}

hsCRP = high sensitivity C-Reactive Protein; MMP-9 = Matrix Metalloproteinase-9, sVEGFR-2 = soluble Vascular Endothelial Growth Factor Receptor-2, SD = Standard Deviation; $\mathrm{p}=$ probability "unpaired $\mathrm{t}$ test" result test; * $=$ significance $(\mathrm{p}<0.05)$. 
Table 3. Differences of MMP-9/sVEGFR-2 Ratio between Hypertensive Non Obese and Hypertensive Obese Subjects

\begin{tabular}{lcccc}
\hline Parameter & & $\begin{array}{c}\text { Hypertensive Non Obese } \\
(\mathrm{n}=10)\end{array}$ & $\begin{array}{c}\text { Hypertensive Obese } \\
(\mathrm{n}=34)\end{array}$ & $\mathrm{p}$ \\
\hline MMP-9/sVEGFR-2 $<31.53$ & $\mathrm{~N}$ & 8 & 14 & $0.031^{*}$ \\
& $\%$ & $80 \%$ & $41.2 \%$ \\
MMP-9/sVEGFR-2 231.53 & $\mathrm{~N}$ & 2 & 20 \\
& $\%$ & $20 \%$ & $58.8 \%$ \\
\hline
\end{tabular}

MMP-9 = Matrix Metalloproteinase-9, sVEGFR-2 = soluble Vascular Endothelial Growth Factor Receptor-2, $p=$ probability; Chi square test, * $=$ significance $(p<0.05)$.

\section{Table 4. Differences of hsCRP between Hypertensive Non Obese and Hypertensive Obese Subjects}

\begin{tabular}{lccccc}
\hline Variables & $\begin{array}{c}\text { Hypertensive Non Obese } \\
(\mathbf{n}=10)\end{array}$ & $\begin{array}{c}\text { Hypertensive Obese } \\
(\mathbf{n}=34)\end{array}$ & Total & $\mathbf{p}$ \\
\hline $\mathrm{hsCRP} \leq 3 \mathrm{mg} / \mathrm{L}$ & $\mathrm{N}$ & 10 & 26 & 36 & 0.090 \\
& $\%$ & $100 \%$ & $76.5 \%$ & $81.8 \%$ & \\
$\mathrm{hsCRP}>3 \mathrm{mg} / \mathrm{L}$ & $\mathrm{N}$ & 0 & 8 & 8 \\
& $\%$ & $0 \%$ & $23.5 \%$ & $18.2 \%$ \\
\hline
\end{tabular}

hsCRP = high sensitivity C-Reactive Protein, $p=$ probability; Chi square test, ${ }^{*}=$ significance $(p<0.05)$.

Table 5. Association between hsCRP and MMP-9/sVEGFR-2 Ratio in Hypertensive Obese Subjects

\begin{tabular}{|c|c|c|c|c|c|}
\hline hsCRP groups & $\begin{array}{c}\text { MMP-9 /sVEGFR-2 } \\
\text { Group }\end{array}$ & & $\begin{array}{l}\text { Hypertensive } \\
\text { Non Obese }\end{array}$ & $\begin{array}{c}\text { Hypertensive } \\
\text { Obese }\end{array}$ & Total \\
\hline \multirow[t]{6}{*}{$\mathrm{hsCRP} \leq 3 \mathrm{mg} / \mathrm{L}$} & MMP-9/sVEGFR-2 & $\mathrm{N}$ & 8 & 11 & 19 \\
\hline & $<31.53$ & $\%$ & $80 \%$ & $42.3 \%$ & $52.8 \%$ \\
\hline & MMP-9/sVEGFR-2 & $\mathrm{N}$ & 2 & 15 & 17 \\
\hline & $\geq 31.53$ & $\%$ & $20 \%$ & $57.7 \%$ & $47.2 \%$ \\
\hline & Total & $\mathrm{N}$ & 10 & 26 & 36 \\
\hline & & $\%$ & $100 \%$ & $100 \%$ & $100 \%$ \\
\hline \multirow[t]{6}{*}{$\mathrm{hsCRP}>3 \mathrm{mg} / \mathrm{L}$} & MMP-9/sVEGFR-2 & $\mathrm{N}$ & & 3 & 3 \\
\hline & $<31.53$ & $\%$ & & $37.5 \%$ & $37.5 \%$ \\
\hline & MMP-9/sVEGFR-2 & $\mathrm{N}$ & & 5 & 5 \\
\hline & $\geq 31.53$ & $\%$ & & $62.5 \%$ & $62.5 \%$ \\
\hline & Total & $\mathrm{N}$ & & 8 & 8 \\
\hline & & $\%$ & $100 \%$ & $100 \%$ & $100 \%$ \\
\hline
\end{tabular}

hsCRP = high sensitivity C-Reactive Protein; MMP-9 = Matrix Metalloproteinase-9, sVEGFR-2 = soluble Vascular Endothelial Growth Factor Receptor-2. 
The subjects were divided into 2 groups based on hsCRP concentration, namely low to intermediate risk group (hsCRP $\leq 3 \mathrm{mg} / \mathrm{L}$ ) and high risk group (hsCRP $>3$ $\mathrm{mg} / \mathrm{L}$ ). Table 4 shows that $23.5 \%$ of hypertensive obese subjects had hsCRP of $>3 \mathrm{mg} / \mathrm{L}$ and on the contrary, among the hypertensive non obese subjects none had hsCRP $>3 \mathrm{mg} / \mathrm{L}$. So, inflammation was obviously activated in obesity.

Table 5 shows association between hsCRP with MMP-9/sVEGFR-2 ratio in hypertensive obese group. There was association between increasing inflammation with vascular remodeling-repairing process in hypertensive obese subjects.

\section{Discussion}

Hypertension and obesity are risk factors of CV events and they are notoriusly known as proinflammatory conditions. Vascular remodeling is one of the pathomechanisms of atherosclerosis process that increases CV events. Growth and apoptosis of smooth muscle cells, low grade inflammation and vascular fibrosis are dynamic process affecting vascular remodeling.

\section{Analysis of Vascular Remodeling-Repairing Balances in Hypertensive Obese Subjects}

Obviously, vascular remodeling process is increased in hypertensive obese subjects. Similar results showed in studies performed by Dhringa et al. (2009) (12), Tran et al. (2010) (13), and Glowinska-Olszewska et al. (2006) (14). They reported an increased MMP-9 activity as a marker of remodeling process in hypertensive population. $(12,13,14,15,16,17)$.

Plasma MMP-9 is a type gelatinase-B digests gelatin type IV and V collagen, which are ubiquitously found in subendothelial basement membrane. Enhancement of this enzym activity may reveal increased matrix breakdown and vascular inflammation. Those are characteristic of the early stages of vascular remodeling in experimental models of hypertension $(12,13,14,15)$.

Glowinska-Olszewska et al. (2006) (12) reported that changes of plasma MMP indicates altered metabolism of the extracellular matrix (ECM) of vessels and heart muscle. Then it leads to atherosclerotic process in the young patients (14).

Afterwards, Dhringa et al. (2009) reported in community-based samples that higher plasma TIMP-1 and
MMP-9 concentrations were associated with greater risk of hypertension. These findings support the concept that higher circulating levels of matrix remodeling markers may precede of hypertension. Assumingly, these marker might reflect vascular remodeling. Fantin et al. (2010) (16) reported that in apparently healthy elderly, metabolic syndrome was strongly associated with subclinical vascular damage. Abdominal obesity and hypertriglyceridemia are also significant predictors of vascular damage $(12,17)$.

Because the sample of the study is supposed to be representing the mild risk of hypertension population, no significant differences of sVEGFR-2 were noted between hypertensive obese versus hypertensive non-obese patients. This is explains that repairing process still work well as adaptive mechanism in such kind of population.

Actually, VEGFR-2 plays a central role in the proliferation and apoptosis of vascular endothelium. Depletion of VEGFR-2 signaling leads to apoptosis in capillaries. Tran et al. (2010) (17) reported that in experimental model of hypertension Spontaneously Hypertensive Rats (SHRs), increased MMP activities may cleavage VEGFR-2, resulting in endothelial apoptosis and capillary rarefaction in the SHR. This causes cleavage of the extracellular domain of VEGFR-2 at multiple positions (e.g. Leu-Ser | Met-Leu, Leu-Ser | Ile-Arg). This cleavage reduces the ability of the cell to bind VEGF agonist and may be one of the reasons for the enhanced apoptosis in the SHR endothelium. Chronic treatment of the SHR with an MMP inhibitor restores normal cell function and attenuates this patophysiological process (13).

Interestingly, dynamic process of increased remodeling process over repairing process would had begun with increased remodeling-repairing ratio. We have proven this in obese hypertension.

Recent cohort study have demonstrated that hsCRP independently conveyed additive prognostic factor in metabolic syndrome. There was a positive relationship between increased serum levels of CRP and the risk of hypertension in Women's Health Study. Yudkin et al. reported strong correlation between hsCRP and BMI in 107 healthy subjects. Danesh et al. in meta analysis study reported that individuals with increase hsCRP (top tertile) was associated with $\mathrm{CV}$ risk factor after 6 years, with odds ratio of 1.7. $(9,10,18)$.

Increased vascular remodeling over repairing balances in hypertension obesity have been convincingly proved in our study, again this is in relation with inflammation as well. Results of our study did not provide causal relationship, due to limitation of the study design. 


\section{Conclusion}

Inflammation is associated with increased vascular remodeling-repairing balances in hypertensive obese subjects. They are more presenting increased inflammation and dominant remodeling process.

\section{Acknowledgement:}

We thank The Prodia Education and Research Institute, Research Support Department of Prodia Clinical Laboratory, Prodia Clinical Laboratory-Makassar and Prodia Clinical Laboratory-Bandung for their invaluable supports in conducting this research.

\section{References:}

1. Wolk, R, Shamsuzzaman, ASM, Somers, VK. Obesity, Sleep Apnea, and Hypertertension. Hypertension 2003; 42: $1067-$ 74.

2. Aneja, A, El-Atat, F, McFarlane S.I, Sower, J.R. Hypertension and Obesity. Endocr J, 2004; 169-94.

3. Kotsis V, Stabouli S, Papakatsika S, Rizos Z, Parati G. Mechanisms of obesity-induced Hypertension. Hyperten Res 2010; 33: 386-93.

4. Narkiewicz,K. Obesity and Hypertension - the issue is more complex than we thought, Nephrol Dial Transplant 2006; 21: 264-7.

5. Rahmouni, K, Correia, MLG, Haynes, WG, Mark, AL, ObesityAssociated Hypertension New Insights Into Mechanisms. Hypertension 2005; 45: 9-14.

6. Intengan HD, Schiffrin EL. Vascular Remodeling in Hypertension: Roles of Apoptosis, Inflammation and
Fibrosis, Hypertension 2001; 38 (part 2): 581-7.

7. Schiffrin, E.L, Touyz, R.M. From Bedside to Bench to Bedside: Role of renin-angiotensin-aldosterone system in remodeling of resistance arteries in hypertension, Am J Physiol Heart Circ Physiol, 2004; 287: H435-H46.

8. Touyz, RM. Molecular and Cellular Mechanisms in vascular injury in hypertension: role of angiotensin II, Curr Opin Nephrol Hypertens 2005; 14: 125-31.

9. Tam C.S, Clement, K, Baur, L.A, Tordjman, J. Obesity and low grade inflammation: a paediatric prespective, Obes Rev, 2010; 11: 118-26

10. Savoia, C, Schiffrin, EL. Inflammation in Hypertension, Curr Opin Nephrol Hypertens, 2006; 15: 152-8.

11. JNC, The Seventh Report of the Joint National Committee on Prevention, Detection, Evaluation, and Treatment of High Blood Pressure. JAMA 2003; 289: 2560-72.

12. Sasamura, H, Shimizu-Hirota, R, Saruta, T. Extracellular Matrix Remodeling in Hypertension, Curr Hypertens Rev 2005; 1 : 51-60.

13. Briones, AM, Arribas, SM, Salaices, M, Role of Extracellular Matrix in Vascular Remodeling of Hypertension, Curr Opin Nephrol Hypertens 2010; 19: 187-94.

14. Glowinska-Olszewska B, Urban M, Florys, B, Selected Matrix Metalloproteinases (MMP-2, MMP-9) in Obes Children and Adolescents, Endocrynol Diabetol Chor Przemainy Materii Wieku Rozw. 2006; 12(3): 179-83.

15. Dhingra, R, Pencina, MJ, Scharde $P$ et al., Relation of Matrix Remodeling Biomarkers to Blood Pressure Progression and Incidence of Hypertension in the Community, Circulation.2006; 119: 1101-07

16. Fantin F, Di Francesco V, Rossi A, Giuliano K, Marino F, Cazzadori M, et al. Abdominal Obesity and Subclinical Vascular Damage in the Elderly. J Hypertens, 2010. 28: 333-9.

17. Tran, ED, DeLano, FA, Schmid - Schonbein, GW. Enhanced Matrix Metalloproteinase Activity in the Spontaneously Hypertensive Rat: VEGFR-2 Cleavage, Endothelial Apoptosis, and Capillary Rarefaction. J Vasc Res 2010; 47: 423-31.

18. Yanai $\mathrm{H}$, Tomono $\mathrm{Y}$, Ito $\mathrm{K}$, Furutani $\mathrm{N}$, Yoshida $\mathrm{H}$, Tada N. The Underlying Mechanisms for Development of Hypertension in The Metabolic Syndrome, Nutrition J, 2008; 7: 10. 